Stabi I ity test s of the $\mathrm{Nb}$ - $\mathrm{Ti}$ cabl e i $\mathrm{n}$ - condui $\mathrm{t}$ super conduct or wi th bare strands for demonst $r$ at i on of the Large Hel i cal Devi ce pol oi dal fi el d coi I s

\begin{tabular}{|l|l|}
\hline $\begin{array}{l}\text { jour nal or } \\
\text { publ i cat i on ti t l e }\end{array}$ & I EEE Tr ansact i ons on Nagnet i cs \\
\hline vol une & Vol . 30 \\
\hline nunber & I ssue 4| Par t 2 \\
\hline page r ange & pp. 1705- 1709 \\
\hline year & 1994 07- 01 \\
\hline URL & ht t p: //hdl . handl e. net /10655/2234 \\
\hline
\end{tabular}




\title{
Stability Tests of the Nb-Ti Cable-in-Conduit Superconductor with Bare Strands for Demonstration of the Large Helical Device Poloidal Field Coils
}

\author{
National Institute for Fusion Science, Oroshi-cho, Toki, Gifu 509-52, Japan \\ H. Ogata, T. Yoshida, M. Ono, H. Takano, S. Ioka \\ Toshiba Corporation, Chiyoda-ku, Tokyo 100, Japan \\ N. Aoki \\ Showa Electric Wire \& Cable Co., Ltd, Kawasaki, Kanagawa 210, Japan \\ J. W. Lue \\ Oak Ridge National Laboratory, Oak Ridge, TN37831-8040 \\ D. Kasao \\ Kyushu University, Fukuoka 812, Japan
}

K. Takahata, T. Mito, T. Satow, N. Yanagi, M. Sakamoto, S. Yamada, A. Nishimura, J. Yamamoto, O. Motojima

\begin{abstract}
Stability and quench experiments of a $\mathrm{Nb}-\mathrm{Ti}$ cable-in-conduit superconductor with bare strands have been carried out to determine the performance of the poloidal coil for the Large Helical Device (LHD). The conductor was formed into a double-pancake coil named IV-S and was mounted on TOKI-PF - a previously tested R\&D coil. In excitation tests at 7.4 8.3K, the IV-S coil reached the critical currents without premature quenches. Stability tests at $7.5 \mathrm{~K}$ indicated that the limiting current exceeds $20 \mathrm{kA}$, which is the nominal operating current of the LHD poloidal coils. These results demonstrated that the stability of the chosen conductor with bare strands is high enough for the LHD.
\end{abstract}

\section{INTRODUCTION}

The Large Helical Device (LHD) is a heliotron type fusion experimental device and has been constructed since 1990 [1]. One of the special futures of the $\mathrm{LHD}$ is that all magnetic systems are superconducting. The LHD has a pair of helical coils and three pairs of poloidal coils. Inner vertical (IV) coils, which are the smallest pair in the poloidal coils, have been completed already. Inner shaping (IS) coils are now under construction. Outer vertical (OV) coils, of which diameter is $11.3 \mathrm{~m}$, will start from 1994. Conductors of the IV and IS coils are Nb-Ti cable-in-conduit types as shown in Table I. Both conductors have almost the same specifications except for the copper ratio. As for the IS conductor, the NbTi fraction of the strand was reduced because the maximum field is lower than the IV coil. In this paper, we deal with stability of the conductor used for the IV and IS coils.

Before the construction of the IV coil, some R\&D's have been performed. We first made a demonstration coil named

Manuscript received September 20, 1993.
TOKI-PF [2], [3]. In the previous experiments of TOKI-PF, several problems were found out [4]. First the coil quenched before reaching the critical point and the training behaviors were observed. Second the limiting current was observed at $15 \mathrm{kA}$, which was lower than the expected value. We considered that the formvar coating on the strand surface had bad influence on the stability due to the low heat transfer and uneven current distribution. After the experiments, we decided to remove the insulation around the strands in order to improve the stability. We then constructed a double pancake coil with the improved conductor and named IV-S. The IV-S was energized together with TOKI-PF. In this paper, we make a comparison of stability between the TOKIPF and IV-S coils. We also discuss about the stability of the IV conductors.

Table I

Principal specifications of the $\mathrm{IV}$ and IS conductors

\begin{tabular}{lll}
\hline Conductor & IV & IS (Design) \\
\hline Type & Cable-in-conduit & Cable-in-conduit \\
Superconducting material & Nb-Ti & Nb-Ti \\
Conduit dimension & $23.0 \mathrm{~mm} \times 27.6 \mathrm{~mm}$ & $23.0 \mathrm{~mm} \times 27.6 \mathrm{~mm}$ \\
\multicolumn{1}{c}{ thickness } & $3.0 \mathrm{~mm}$ & $3.0 \mathrm{~mm}$ \\
Void fraction & 0.377 & 0.38 \\
Strand diameter & $0.762 \mathrm{~mm}$ & $0.760 \mathrm{~mm}$ \\
Number of strands & 486 & 486 \\
Nb-Ti:Cu & $1: 2.69$ & $1: 3.52$ \\
Strand surface & $\mathrm{Bare}$ & $\mathrm{Bare}$ \\
Operating Current & $20.8 \mathrm{kA}$ & $21.6 \mathrm{kA}$ \\
Maximum Field & $6.5 \mathrm{~T}$ & $5.4 \mathrm{~T}$ \\
Operating temperature & $4.5 \mathrm{~K}-4.8 \mathrm{~K}$ & $4.5 \mathrm{~K}-4.8 \mathrm{~K}$ \\
$\quad<1.0 \mathrm{MPa}$ & $<1.0 \mathrm{MPa}$ \\
\hline
\end{tabular}


Table II

Comparison of the TOKI-PF and IV-S conductors

\begin{tabular}{lll}
\hline Conductor & TOKI-PF & IV-S \\
\hline Type & Cable-in-conduit & Cable-in-conduit \\
Superconducting material & Nb-Ti & Nb-Ti \\
Conduit dimension & $17.0 \mathrm{~mm} \times 22.5 \mathrm{~mm}$ & $17.0 \mathrm{~mm} \times 22.5 \mathrm{~mm}$ \\
$\quad$ thickness & $1.0 \mathrm{~mm}$ & $1.0 \mathrm{~mm}$ \\
Void fraction & 0.40 & 0.345 \\
Strand diameter & $0.673 \mathrm{~mm}$ & $0.707 \mathrm{~mm}$ \\
Number of strands & 486 & 486 \\
Nb-Ti:Cu:Cu-Ni & $1: 1.65: 0.4$ & $1: 2.54: 0$ \\
Strand surface & Formvar coating $(11 \mu \mathrm{m})$ & Bare \\
\hline
\end{tabular}

Table III

Principal specifications of the TOKI-PF and IV-S coils

\begin{tabular}{lll}
\hline Coil & TOKI-PF & IV-S \\
\hline Configuration & Two double pancakes & One double pancake \\
Inner radius & $0.6 \mathrm{~m}$ & $0.6 \mathrm{~m}$ \\
Outer radius & $0.82 \mathrm{~m}$ & $0.76 \mathrm{~m}$ \\
Height & $0.11 \mathrm{~m}$ & $0.052 \mathrm{~m}$ \\
Number of turns & 40 & 16 \\
Cooling method & Forced flow & Forced flow \\
Operating temperature & $>4.5 \mathrm{~K}$ & $>4.5 \mathrm{~K}$ \\
& $<1 \mathrm{MPa}$ & $<1 \mathrm{MPa}$ \\
Number of cooling paths & $4 \mathrm{paths}$ & $2 \mathrm{paths}$ \\
Design mass flow rate & $16 \mathrm{~g} / \mathrm{s}$ (total) & $10 \mathrm{~g} / \mathrm{s}$ (total) \\
Cooling path length & $45 \mathrm{m \times 4}$ & $34.5 \mathrm{~m} \times 2$ \\
\hline
\end{tabular}

\section{CONDUCTOR AND COIL ARRANGEMENT}

Comparison of the TOKI-PF and IV-S conductors is summarized in Table II. The IV-S conductor was designed concentrating on the stability. The most important difference is the surface of the strands. We removed the formvar which was used on the strand surface for TOKI-PF coil. Moreover, we remove $\mathrm{Cu}-\mathrm{Ni}$ in the strand to increase the copper ratio. The void fraction was also reduced by increasing the strand diameter in order to avoid strand movements. As for the conduit, both conductors have the same dimensions. Fig. 1 is the photograph of the cross-section of the IV-S conductor.

The conductor of $70 \mathrm{~m}$ was formed into a double-pancake and mounted on TOKI-PF. Specifications of the TOKI-PF and IV-S coils are listed in Table III. Both coils have the same inner radius of $0.6 \mathrm{~m}$. The IV-S coil was attached to TOKI-PF truing up the center as shown in Fig. 2. The two coils were joined up in series and both ends were connected to current leads. Dotted lines in Fig. 3 indicate a current path. Cooling paths are also indicated schematically in Fig. 3 . The coils consist of six parallel flow paths. Supercritical helium (SHE) flows from the inner turns to the outer turns with a pressure of $1 \mathrm{MPa}$ or less. Design mass flow rates are 10

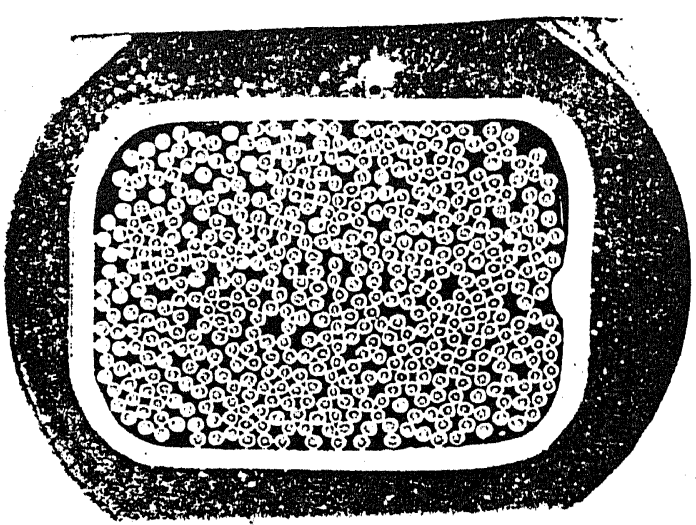

Fig. 1 Photograph of the cross-section of the IV-S conductor

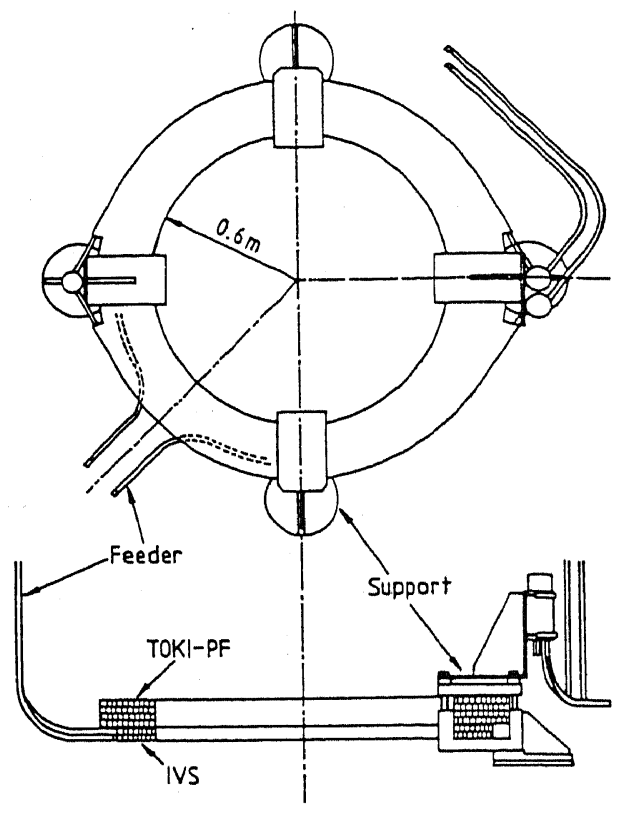

Fig. 2 Coil arrangement

$\mathrm{g} / \mathrm{sec}$ for IV-S and $16 \mathrm{~g} / \mathrm{sec}$ for TOKI-PF.

Peak magnetic fields are $2.7 \mathrm{~T}$ in IV-S and $2.8 \mathrm{~T}$ in TOKI$\mathrm{PF}$ with the current of $20 \mathrm{kA}$. These fields are lower compared with the IV and IS coils of LHD; a maximum field of IV is $6.5 \mathrm{~T}$ at $20.8 \mathrm{kA}$ as shown in Table I. Therefore, we performed the experiments at higher temperature, 7.4 8.3 K, to bring a load close to the IV and IS coils.

\section{EXPERIMENTAL PROCEDURE}

In the experiments, we concentrated on the following two properties; one is operating limits and the other is the stability margin. Fig. 3 shows instrumentations required for the experiments. Resistive heaters (RHl and RH2) were attached on the inlet pipes for the both coils to increase the SHE temperature. Inductive heaters $(\mathrm{IHI} \sim \mathrm{IH} 6)$ were wound 


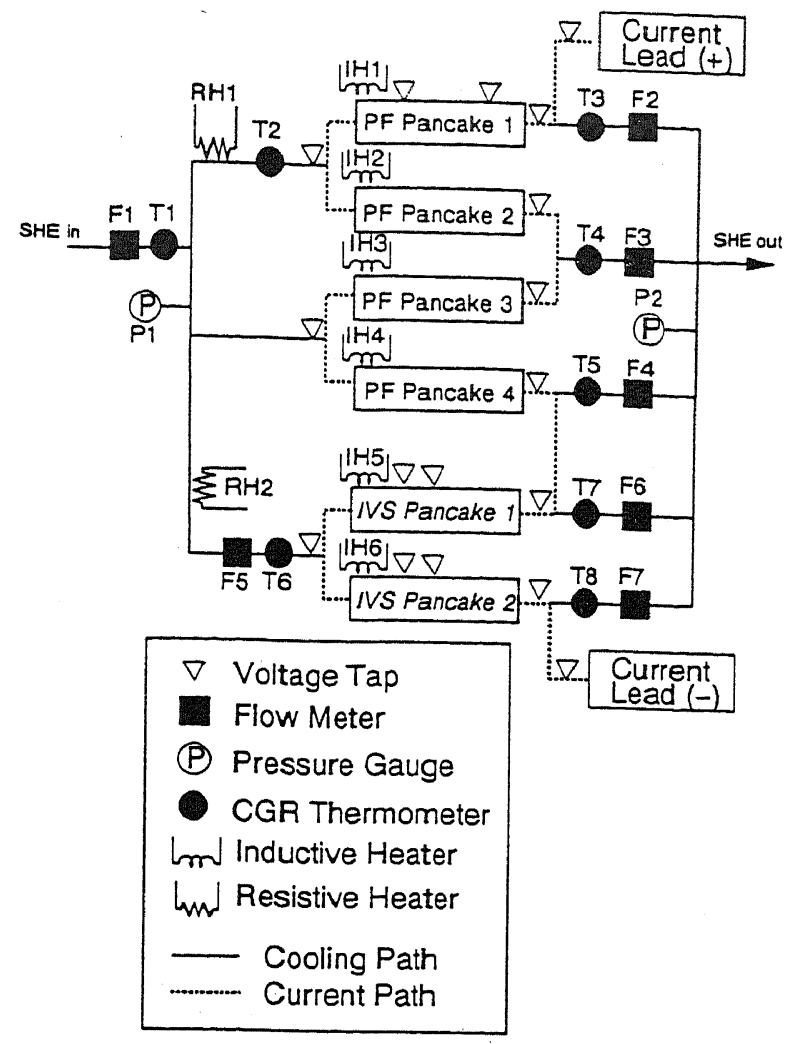

Fig. 3 Instrumentations of the experiment

around the conductor near the SHE inlet in order to measure the stability margin. Flow meters $(F)$, carbon-glass-resistor (CGR) thermometers $(T)$ and pressure gauges $(P)$ were installed on the inlet and outlet pipes. A normal zone was detected by voltage taps.

Both current and temperature limits were measured with regard to the operating limits. First we measured the quench current under the condition that the temperature was constant, from $4.5 \mathrm{~K}$ to $8.1 \mathrm{~K}$. Second we measured a temperature at which the coil just quenched under the condition that the current was constant. The temperature was controlled by the resistive heaters. By comparing the two results, we could estimate the effect of mechanical disturbances which may appear when ramping up the current. The temperature limit is not affected by the disturbances because the electro-magnetic force is constant. Therefore, the limit may correspond to the current sharing temperature. The quench current does not necessarily agree with the critical current because of the disturbances.

The stability margin was measured by the inductive heaters with a length of $0.1 \mathrm{~m}$ and 200 turns. The power supply consists of silicon controlled rectifiers, a capacitor bank of $0.4 \mathrm{mF}$ and $1 \mathrm{kV}$. In the experiments, current discharges were obtained with an oscillation frequency of $500 \mathrm{~Hz}$ and a decay time constant of $5 \mathrm{msec}$. It is usually difficult to calibrate an input energy. We, then, apply a calorimetric method. Fig. 4 shows a typical time variation of

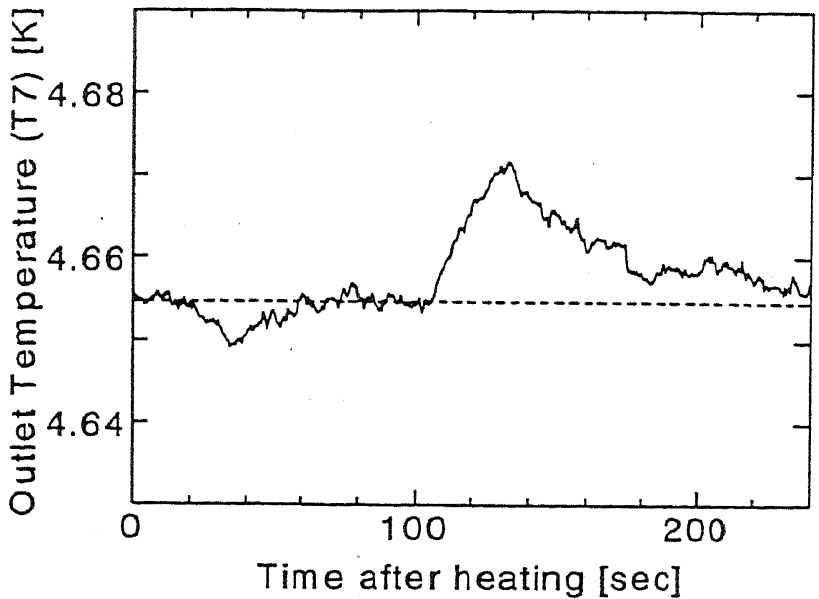

Fig. 4 Time variation of the outlet temperature (T7) after heating by the inductive heater (IH5)

the outlet temperature (T7) after heating by the heater (IH5). At that time, the capacitor bank was charged up to $520 \mathrm{~V}$. The temperature increased from the initial temperature, $4.655 \mathrm{~K}$ after $100 \mathrm{sec}$. If assuming that the heat did not run away to the neighboring layer, the input energy can be calculated from the integration of the increase of helium enthalpy.

The margin of IV-S was measured at the temperature of $4.5 \mathrm{~K}$ and $7.5 \mathrm{~K}$ with the pressure of $1.0 \mathrm{MPa}$ and $0.5 \mathrm{MPa}$. First the coils were energized to a certain current. Then the conductor was heated by the inductive heater (IH5). If the coil did not quench, the capacitor bank was charged up to a slightly higher voltage and then discharged. The heating was repeated with the sufficient intervals until the coil quenched.

\section{RESULTS}

\section{A. Operating Limits}

In the beginning of the experiments, the current limits were measured at various temperatures. The pressure of SHE was $1.0 \mathrm{MPa}$ and current sweep rate was $50 \mathrm{~A} / \mathrm{sec}$ for all excitations. Fig. 5 and Fig. 6 show the quench points on the load line for the TOKI-PF and IV-S coils, respectively. In the figures, critical currents $\left(\mathrm{I}_{\mathrm{C}, \mathrm{cal}}\right)$ extrapolated from $4.2 \mathrm{~K}$ single strand short sample measurements up to $7 \mathrm{~T}$ are also presented. The TOKI-PF coil quenched at $4.5 \mathrm{~K}, 22.5 \mathrm{kA}$ and $3.15 \mathrm{~T}$, which was $45 \%$ of the critical point. In the previous tests, the quench current was also measured. The results are shown in Fig. 5 as a single operation. The quench current was $26.3 \mathrm{kA}$ at $2.83 \mathrm{~T}$. It should be noted that the products of the quench current and the magnetic field are almost the same between the single and the combined operation. That indicates that the quench origin lies in the electro-magnetic force. The quench current at $7.4 \mathrm{~K}$ was $14.9 \mathrm{kA}, 65 \%$ of the critical current. 


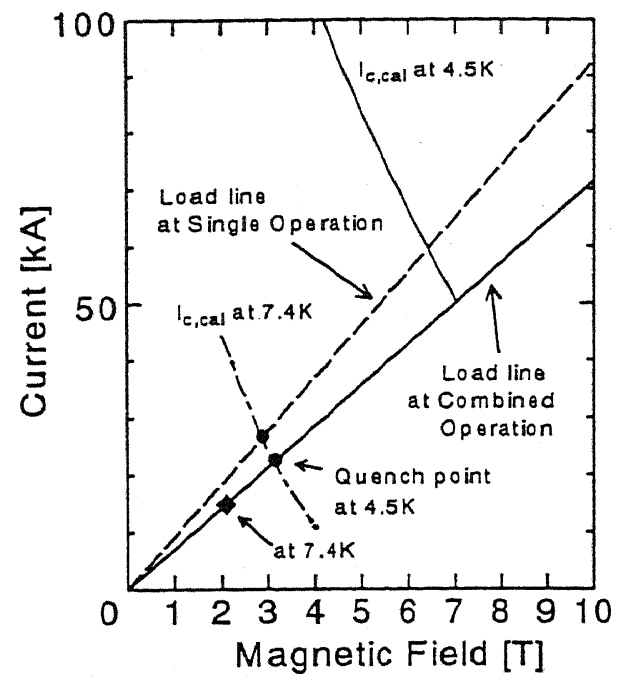

Fig. 5 Quench currents of the TOKI-PF coil on the load line

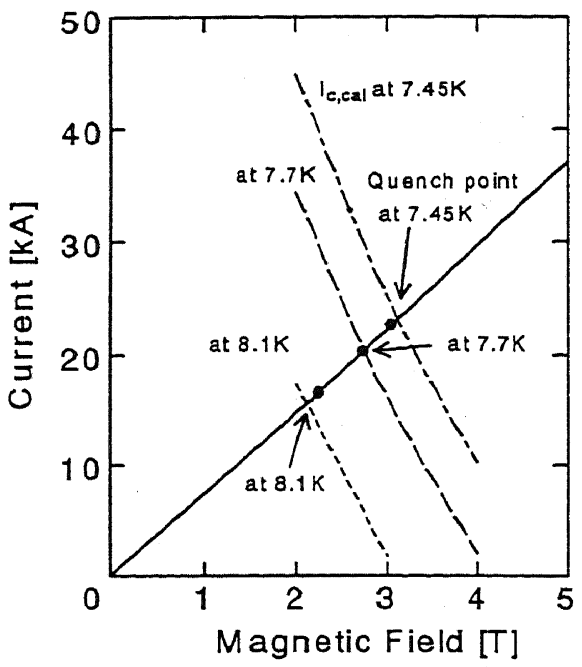

Fig. 6 Quench currents of the IV-S coil on the load line

On the other hand, the IV-S coil quenched at almost the same current as the critical current, $16.6 \mathrm{kA}$ at $8.1 \mathrm{~K}, 20.3$ $\mathrm{kA}$ at $7.7 \mathrm{~K}$ and $22.6 \mathrm{kA}$ at $7.45 \mathrm{~K}$. We could not measure the quench current under $7.45 \mathrm{~K}$ because the TOKI-PF coil quenched before IV-S. The differences between the quench and the calculated critical current may be caused by the error of the extrapolation. The temperature limits were also measured in order to clarify the critical points. The temperature limit must correspond to the current sharing temperature because the limit was not affected by the wire movement. The results are summarized in Fig. 7. The closed and the open circles indicate the current and the temperature limits, respectively. Both limits lie in the same line as is evident from the figure. Then it is concluded that the IV-S coil can be energized up to the critical point without any

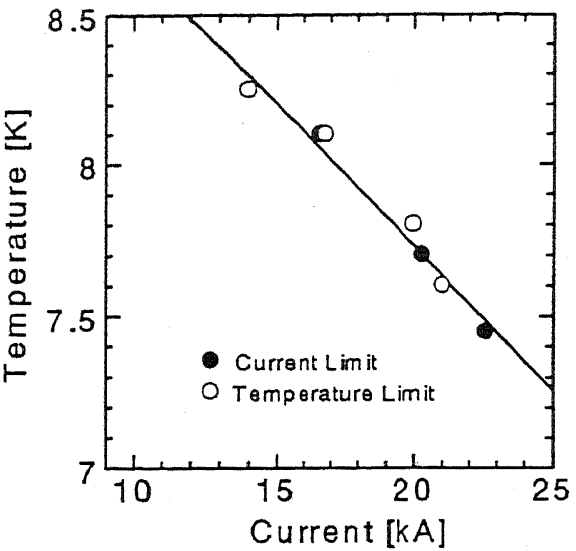

Fig. 7 Comparison between the current and temperature limits

degradation.

The results of the limit measurements confirmed that the IV-S coil has much higher performances than TOKI-PF. There are two reasons for this improvement of the performance. One is the decrease of mechanical disturbances due to the strand movements since the void fraction was reduced for the IV-S coil. The other is the improvement of the stability margin due to the removal of the insulation on the strand surface. We performed the stability margin measurements in order to confirm the above reasons.

\section{B. Stability Margin}

Fig. 8 shows the results of the stability margin measurements at $4.5 \mathrm{~K}$. As for the TOKI-PF coil, the data obtained in the previous tests are presented. The solid and the dashed line shows the helium enthalpy calculated by the following equation on the IV-S and the TOKI-PF coil, respectively.

$$
\Delta H=(1-f) / f \int_{T_{b}}^{T_{s h}} \rho_{H e} C_{p} d T
$$

where $f$ is the volume fraction of the strands inside the cable space, $\mathrm{T}_{\mathrm{b}}$ and $\mathrm{T}_{\mathrm{sh}}$ are the bath and the current sharing temperature, respectively, $\rho \mathrm{He}$ is the helium density, and $\mathrm{C}_{\mathrm{p}}$ is the specific heat at. constant pressure of helium. The limiting current [5], [6] was observed at $15 \mathrm{kA}$ on the TOKIPF coil. The margin was below $10^{5} \mathrm{~J} / \mathrm{m}^{3}$ when the current was larger than $15 \mathrm{kA}$, and about $4 \times 10^{4} \mathrm{~J} / \mathrm{m}^{3}$ at the quench current, $26.3 \mathrm{kA}$. The margin of IV-S was measured at only $21 \mathrm{kA}$, which is the nominal current of the IV and IS coils The coil did not quench up to $8 \times 10^{5} \mathrm{~J} / \mathrm{m}^{3}$, and we could not quench it because of limitations of the power supply. It was, however, evident that the margin stayed in the upper stability region, and the limiting current was higher than 21 $\mathrm{kA}$. It is concluded that the stability was improved by removing the insulation on the strand surface. 


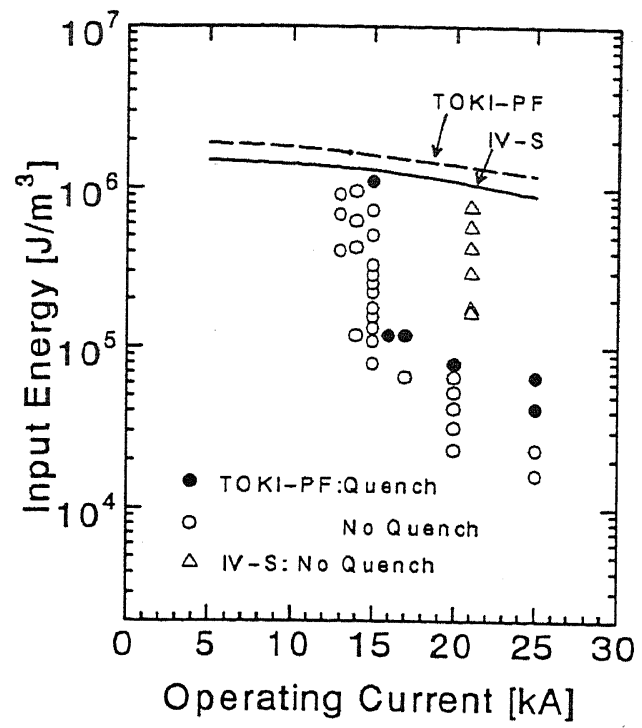

Fig. 8 Results of the stability margin measurements at $4.5 \mathrm{~K}$.

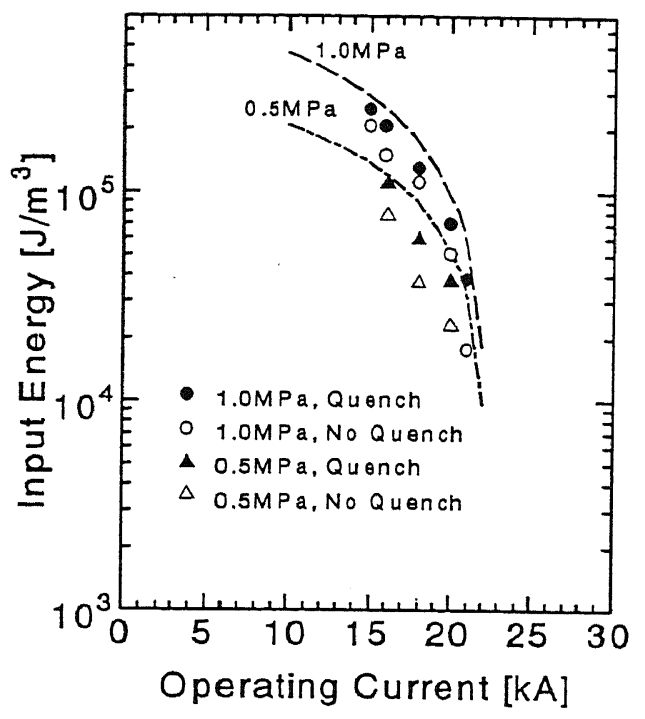

Fig. 9 Results of the stability margin measurements at $7.5 \mathrm{~K}$ on the IV-S coil.

The margin of IV-S was then measured at $7.5 \mathrm{~K}$ at a pressure of $1.0 \mathrm{MPa}$ or $0.5 \mathrm{MPa}$. The results are shown in Fig. 9. The dashed and the dash-dotted line indicates the available helium enthalpy calculated by (1). The margins were all very close to the calculated available enthalpy in the both cases of $1.0 \mathrm{MPa}$ and $0.5 \mathrm{MPa}$. Thus the conductor stayed in the upper stability region up to $21 \mathrm{kA}$, which was about $94 \%$ of the critical current. It can be concluded that the limiting current is higher than the critical current under the present conditions. It can also be inferred that energy deposition due to strand movements must be less than $3 \times 104$ $\mathrm{J} / \mathrm{m}^{3}$, the measured stability margin at $21 \mathrm{kA}$, because the coil did not quench up to $21 \mathrm{kA}$. The inferential energy deposition was lower than TOKI-PF, $4 \times 10^{4} \mathrm{~J} / \mathrm{m}^{3}$. The reason of this may be caused by reducing the void fraction.

If assuming that the dimensions are the same, the limiting current is proportional to $\left(T_{c}-T_{b}\right)^{1 / 2} \rho^{-1 / 2}$, where $T_{c}$ and $T_{b}$ are the critical and the bath temperature, and $\rho$ is the resistivity of copper [5]-[7]. As for IV-S, the limiting current was higher than $21 \mathrm{kA}$ at $7.5 \mathrm{~K}$. In this condition, $\left(\mathrm{T}_{\mathrm{C}^{-}}\right.$ $\left.\mathrm{T}_{\mathrm{b}}\right)^{1 / 2} \rho^{-1 / 2}$ is estimated to be $5.8 \times 10^{4}$. On the other hand, $\left(T_{C}-T_{b}\right)^{1 / 2} \rho^{-1 / 2}$ is $7.4 \times 10^{4}$ at the nominal condition of the IV coil, $B=6.5 \mathrm{~T}, \mathrm{I}=20.8 \mathrm{kA}$ and $\rho=4 \times 10^{-10} \Omega \mathrm{m}$. This value is 1.3 times higher than IV-S. Thus it can be expected that the limiting current of the IV coil is higher than the nominal operating current.

\section{CONCLUSIONS}

The Nb-Ti cable-in-conduit superconductor with bare strands was developed, and stability and quench experiments were carried out in the form of a double-pancake to demonstrate the performance of the poloidal field coil for the LHD. A summary of the results is shown below.

(1) The quench current and the stability margin were improved by removing the insulation of strand surfaces.

(2) The energy deposit due to strand movements was reduced by the reduction of the void fraction.

(3) It can be expected from the stability margin measurements that the limiting current is higher than the nominal current for the IV and IS coils.

\section{REFERENCES}

[1] T. Satow, et al., "Present status of design and manufacture of the superconducting magnets for the Large Helical Device," IEEE Trans. on Appl. Supercon., Vol. 3, pp. 365-368, March 1993.

[2] K. Takahata, et al., "Design and fabrication of forced-flow coils as an R\&D program for Large Helical Device," IEEE Trans. on Magn., Vol. 27, pp. 2353 2356, March 1991.

[3] S. Mizumaki, et al., "Fabrication of the R\&D forced-flow poloidal coil (TOKI-PF)," Fusion Engineering Design, Vol. 20, pp. 153-159, 1993.

[4] K. Takahata, et al., "Experimental results of the R\&D forced-flow poloidal coil (TOKI-PF)," Fusion Engineering Design, Vol. 20, pp. 161-166, 1993.

[5] Lawrence Dresner, "Parametric study of the stability margin of cable-inconduit superconductors: Theory," IEEE Trans. on Magn., Vol. 17, pp. 753756, January 1981.

[6] J. W .Lue and J. R .Miller, "Parametric study of the stability margin of cable-in-conduit superconductors: Experiment," IEEE Trans. on Magn., Vol. 17, pp. 757-760, January 1981.

[7] T. Ando, M. Nishi and S. Shimamoto, "Measurements of the stability margin of a $\mathrm{Nb}_{3} \mathrm{Sn}$ cable-in-conduit conductor," IEEE Trans. on Magn., Vol. 25, pp. 2386-2389, March 1988 . 